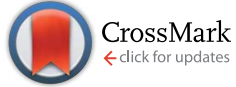

Cite this: J. Mater. Chem. A, 2015, 3, 21760

Received 17th July 2015

Accepted 18th September 2015

DOI: $10.1039 / \mathrm{c} 5 \mathrm{ta} 05470 \mathrm{~b}$

www.rsc.org/MaterialsA

\section{Chemical engineering of methylammonium lead iodide/bromide perovskites: tuning of opto- electronic properties and photovoltaic performance $\uparrow$}

\author{
Byung-wook Park, ${ }^{a}$ Bertrand Philippe, ${ }^{\mathrm{b}}$ Sagar M. Jain, ${ }^{a}$ Xiaoliang Zhang, ${ }^{a}$ \\ Tomas Edvinsson, ${ }^{\mathrm{C}}$ Håkan Rensmo, ${ }^{\mathrm{b}}$ Burkhard Zietz ${ }^{\mathrm{a}}$ and Gerrit Boschloo*a
}

\begin{abstract}
Hybrid (organic-inorganic) lead trihalide perovskites have attracted much attention in recent years due to their exceptionally promising potential for application in solar cells. Here a controlled one-step method is presented where $\mathrm{PbCl}_{2}$ is combined with three equivalents methylammonium halide (MAX, with $\mathrm{X}=1$ and/or $\mathrm{Br}$ ) in polar solvents to form $\mathrm{MAPb}\left(l_{1-x} \mathrm{Br}_{x}\right)_{3}$ perovskite films upon annealing in air at $145^{\circ} \mathrm{C}$. The procedure allows for a linear increment of the semiconductor bandgap from $1.60 \mathrm{eV}$ to $2.33 \mathrm{eV}$ by increasing the $\mathrm{Br}$ content. A transition from a tetragonal to a cubic structure is found when the $\mathrm{Br}$ fraction is larger than 0.3. X-ray photoelectron spectroscopy investigations shows that the increase of $\mathrm{Br}$ content is accompanied by a shift of the valence band edge to lower energy. Simultaneously, the conduction band moves to higher energy, but this shift is less pronounced. Time-resolved single-photon counting experiments of the perovskite materials on mesoporous $\mathrm{TiO}_{2}$ show faster decay kinetics for $\mathrm{Br}$ containing perovskites, indicative of improved electron injection into $\mathrm{TiO}_{2}$. Interestingly, kinetics of $\mathrm{MAPbl}_{2.7} \mathrm{Br}_{0.3} \mathrm{Cl}_{y}$ on $\mathrm{TiO}_{2}$ scaffold became faster after prolonged excitation during the measurement. In solar cell devices, $\mathrm{MAPbl}_{2.7} \mathrm{Br}_{0.3} \mathrm{Cl}_{y}$ yielded best performance, giving more than $14 \%$ power conversion efficiency when used in combination with an $\mathrm{n}$-type contact consisting of fluorine-doped tinoxide glass coated with dense $\mathrm{TiO}_{2}$ and a mesoporous $\mathrm{Al}_{2} \mathrm{O}_{3}$ scaffold, and a p-type contact, spiro-MeOTAD/Ag.
\end{abstract}

\section{Introduction}

Hybrid (organic-inorganic) metal halide perovskite materials are highly interesting for application in very efficient low-cost solar cells. ${ }^{1}$ Within a few years of active research of these material for photovoltaic applications, power conversion efficiencies have already reached about $20 \%$ for small devices ${ }^{2}$ and may soon approach and surpass the record efficiencies of silicon and thin film technologies, such as $\mathrm{Cu}(\mathrm{In}, \mathrm{Ga}) \mathrm{Se}_{2}$ and CdTe.

Mitzi and co-workers have studied the properties of a large range of hybrid lead halide perovskites in detail. ${ }^{3}$ These materials were used as the active layer in light emitting diodes and field-effect transistors. ${ }^{3}$ Hybrid lead halide perovskites have also the potential to be used in photovoltaics, with various device

\footnotetext{
${ }^{a}$ Uppsala University, Department of Chemistry-Ångström Laboratory, Physical Chemistry, Box 523, SE 75120 Uppsala, Sweden. E-mail: gerrit.boschloo@kemi.uu.se ${ }^{b}$ Uppsala University, Department of Physics and Astronomy, Molecular and Condensed Matter Physics, Box 516, SE 75120 Uppsala, Sweden

${ }^{c}$ Uppsala University, Department of Chemistry-Ångström Laboratory, Inorganic Chemistry, Box 538, SE 75121 Uppsala, Sweden

$\dagger$ Electronic supplementary information (ESI) available. See DOI: 10.1039/c5ta05470b
}

architectures and efficiencies reported over 20\%., ${ }^{2,5-12}$ Hybrid lead halide perovskite materials can be manufactured by simple solution processes, as well as by vacuum evaporation, and their optical, electronic and morphological properties can be tuned by changing the chemical composition, e.g. changing the organic cation, the metal atom and/or the halide..$^{13-15}$

Tunability of the semiconductor bandgap is a very attractive feature for solar cell materials. Specifically, it allows for devices with a specific color, or for semi-transparent solar cells that can be used as top cells in tandem devices. Among the hybrid lead halide perovskites, methylammonium lead triiodide ( $\left.\mathrm{MAPbI}_{3}\right)$ is the most investigated material, exhibiting a bandgap of around $1.5 \mathrm{eV},{ }^{\mathbf{1 0}, 11}$ whereas $\mathrm{MAPbBr}_{3}$ presents a larger bandgap of $2.2 \mathrm{eV} \cdot{ }^{11}$ Noh et al. were first to demonstrate that the bandgap of these materials can be fine-tuned by mixing iodide and bromide. Interestingly, bromide-containing perovskites were found to display better stability under moist air conditions. ${ }^{11}$ By comparison, $\mathrm{MAPbCl}_{3}$ possesses a large bandgap of $3.1 \mathrm{eV} \cdot{ }^{16} \mathrm{In}$ mixed halide preparations where chloride-based precursors are used, however, no significant inclusion of chloride is observed in the perovskite crystal structure. Instead it appears either as separate $\mathrm{MAPbCl}_{3}$ crystals, ${ }^{\mathbf{1 7}, 18}$ or it disappears upon annealing. ${ }^{19}$ Nevertheless, the chloride content in the precursor 
solution plays an important role in the realization of good quality perovskite materials, ${ }^{18}$ presumably due to the formation of an intermediate phase.

In this work, we have studied the formation of $\operatorname{MAPb}\left(\mathrm{I}_{1-x^{-}}\right.$ $\left.\mathrm{Br}_{x}\right)_{3}(\mathrm{Cl})_{y}$ materials, where $x$ is the fraction of bromide, using $\mathrm{PbCl}_{2}$ as the lead precursor in a one-step solution-based method. A similar approach was used recently by Suarez et al. ${ }^{\mathbf{4}}$ We demonstrate the possibility to perform linear bandgap tuning of the hybrid lead halide perovskite, and find an extension of the stability range for the tetragonal crystalline structure. A detailed characterization of the structure and the optoelectric properties of the synthetized materials are presented. Time-resolved single-photon counting experiments suggest improved electron injection from hybrid perovskite into $\mathrm{TiO}_{2}$ when bromide is included. The kinetics found for bromide containing perovskites on $\mathrm{TiO}_{2}$ scaffold became faster upon prolonged excitation during the measurement. Best solar cell results were obtained for $\operatorname{MAPb}\left(\mathrm{I}_{1-x} \mathrm{Br}_{x}\right)_{3}(\mathrm{Cl})_{y}$ with $x=0.1$ on mesoscopic $\mathrm{Al}_{2} \mathrm{O}_{3}$ scaffold layers.

\section{Results and discussion}

\section{Solution-based synthesis of $\mathrm{MAPbX}_{3}$ and structural characterization}

In this study we used $\mathrm{PbCl}_{2}, \mathrm{MAI}$ and $\mathrm{MABr}$ as precursors for hybrid lead halide perovskites, in combination with a mixture of polar solvents: dimethylformamide (DMF) and dimethyl sulfoxide (DMSO) in a ratio of $7: 3$. Tetrahydrofuran (THF, 10 vol\%) was added to the solvent mixture as it was found to decrease the conversion temperature of the organic-inorganic hybrid perovskites (OIHPs) during in the annealing step. The use of $\mathrm{PbCl}_{2}$ as precursor for Br-containing hybrid perovskites is inspired by the use of this salt as precursor in the work by Snaith and co-workers, who obtained efficient perovskites with the structure $\mathrm{MAPbI}_{3-x} \mathrm{Cl}_{x} \cdot{ }^{10}$ In later studies, it was found that the chloride content of this material was less than $5 \% .^{20}$ In our study, the ratio MAX (where X is I or Br) to $\mathrm{PbCl}_{2}$ was kept at $3: 1$ in the preparation. We will refer to the formed materials as $\operatorname{MAPb}\left(\mathrm{I}_{1-x} \mathrm{Br}_{x}\right)_{3}(\mathrm{Cl})_{y}$ to indicate that they were made using chloride-containing precursors. The resulting films do, however, not contain substantial amounts of chloride, as discussed elsewhere. ${ }^{19}$ The overall reaction for formation of the hybrid perovskite is proposed to be:

$$
3 \mathrm{MAX}+\mathrm{PbCl}_{2} \rightarrow \mathrm{MAPbX}_{3}+2 \mathrm{MACl},
$$

where $\mathrm{X}$ is $\mathrm{I}$ and/or Br. Upon annealing, $\mathrm{MACl}$ is decomposed into gas phase components: $\mathrm{MACl}(\mathrm{s}) \rightarrow \mathrm{CH}_{3} \mathrm{NH}_{2}(\mathrm{~g})+\mathrm{HCl}(\mathrm{g})$. However, it is expected that to some degree such reactions already occur in the precursor solution.

Fig. 1 presents the X-ray diffractograms of $\mathrm{MAPbI}_{3}(\mathrm{Cl})_{y}$ and $\mathrm{MAPbBr}_{3}(\mathrm{Cl})_{y}$ materials spin-coated on a mesoscopic $\mathrm{TiO}_{2} /$ glass substrate, either dried in ambient environment $\left(25{ }^{\circ} \mathrm{C}\right)$ or annealed at $145{ }^{\circ} \mathrm{C}$ for 45 minutes (the substrate temperature increased gradually from 20 to $140{ }^{\circ} \mathrm{C}$ in this period, see ESI, Fig. S16 $\dagger$ ). During the drying process of the OIHP precursor solution, THF, which has a boiling point of $66^{\circ} \mathrm{C}$, is expected to evaporate readily, while DMF and DMSO may partially remain in the dried OIHP precursor film. This is confirmed by ATRFTIR, which demonstrates that DMSO is still partially present in the dried precursor films, see Fig. 1c and S1. $\dagger$ The dried precursor films have clear XRD patterns that differ from the $\mathrm{XRD}$ patterns of crystalline $\mathrm{PbCl}_{2}, \mathrm{PbI}_{2}, \mathrm{PbBr}_{2}$ or MA salts (see Fig. 1(c) and S3 in ESI $\dagger$ ). This is a clear indication that a complexation reaction occurs between $\mathrm{PbCl}_{2}$, the halide salts and/or solvents at low temperature. When comparing dried and annealed OIHPs, significant differences are found between $\mathrm{MAPbI}_{3}(\mathrm{Cl})_{y}$ and $\mathrm{MAPbBr}_{3}(\mathrm{Cl})_{y}$, where $\mathrm{MAPbI}_{3}(\mathrm{Cl})_{y}$ is transformed from an intermediate phase at room temperature (see black solid line in Fig. 1(a)) to a tetragonal perovskite structure upon annealing (space group: $14 / \mathrm{mcm}$, see blue solid line in Fig. S2(e)†). ${ }^{21}$ The intermediate phase of OIHP does not match with crystalline phases reported in literature, but is similar to the XRD pattern reported for MACl-assisted formation OIHP. ${ }^{22}$ The $\mathrm{MAPbBr}_{3}(\mathrm{Cl})_{y}$ precursor dried at room temperature has a cubic phase (space group: $P m 3 m$ ) and is very similar to the perovskite structure obtained after annealing at $145{ }^{\circ} \mathrm{C}$ (see Fig. 1(b)). It has a bright yellow lemon color, which changes to a slightly darker yellow color upon annealing. During this process, the XRD pattern is only slightly shifted to lower angles something that may be attributed to the vaporization of MACl (see red solid line in Fig. 1(b)). ${ }^{21-24}$

In the preparation method used, it is easy to obtain mixed $\operatorname{MAPb}\left(\mathrm{I}_{1-x} \mathrm{Br}_{x}\right)_{3}(\mathrm{Cl})_{y}$ perovskites, simply by adding the required proportion of MAI and $\mathrm{MABr}$ to the $\mathrm{PbCl}_{2}$-containing precursor solution. XRD measurements (Fig. 2) show a gradual change from a tetragonal structure, as found for the pure $\mathrm{MAPbI}_{3}$ phase, to a cubic structure, as found for the pure $\mathrm{MAPbBr}_{3}$. The complete XRD patterns for the formed $\operatorname{MAPb}\left(\mathrm{I}_{1-x} \mathrm{Br}_{x}\right)_{3}(\mathrm{Cl})_{y}$ perovskites are shown in ESI (Fig. S2 $\uparrow$ ). Similar observations for mixed I/Br lead perovskite have previously been reported by Noh et al. and Eperon et al. ${ }^{11,25}$ Fig. 2(a) and (b) shows the (110)t peak that transforms into the (100)c peak, and the (224)t peak that becomes (220)c. The calculated lattice parameters for orientations of all OIHPs are summarized in Fig. 2(c). The crystallinity of (110)t for $\mathrm{MAPbI}_{3}(\mathrm{Cl})_{y}$ in this study and in our previous study is observed very much higher than for a standard $\mathrm{MAPbI}_{3}$ film prepared in the absence of chloride ions. ${ }^{21}$ The lattice constants change gradually with the bromide fraction $x$, but a clear singularity is found between $x=0.3$ and 0.4 for all crystal orientations, which we attribute to the transition from a tetragonal to a cubic structure. In the study by Noh et al. ${ }^{11}$ this transition for $\operatorname{MAPb}\left(\mathrm{I}_{1-x} \mathrm{Br}_{x}\right)_{3}(\mathrm{Cl})_{y}$ was found to occur between $x=0.13$ and 0.20 . This suggests that the synthetic details and the choice of precursors are crucial for the composition of this transition, and that the presence of chloride anions in our preparation and extends the stability range of the tetragonal crystalline structure. Eperon et al. ${ }^{25}$ found for $\mathrm{FAPb}\left(\mathrm{I}_{1-x} \mathrm{Br}_{x}\right)_{3}$ perovskite, where FA is formamidinium, a tetragonal phase for $x=0$ to 0.2 and a cubic for $x=0.6$ to 1 , while intermediate preparations did not give crystalline phases.

The degree of crystallinity of the different films is shown in Fig. 2(d), which displays the integrated intensity of the crystalline populations. This value is rather constant value for $\mathrm{Br}$ 



Fig. 1 XRD patterns of room temperature-dried hybrid perovskite precursors and hybrid perovskite thin films. (a) Comparison between dried and annealed OIHP samples of $\mathrm{MAPbBr}_{3}(\mathrm{Cl})_{y}$. (b) Comparison of dried and annealed $\mathrm{MAPbl}_{3}(\mathrm{Cl})_{y}$. (c) ATR-FTIR spectra of dried and annealed $\mathrm{MAPbl}_{3}(\mathrm{Cl})_{y}$.

fractions from $x=0.0$ to 0.3 in $\operatorname{MAPb}\left(\mathrm{I}_{1-x} \mathrm{Br}_{x}\right)_{3}(\mathrm{Cl})_{y}$. From $x=$ 0.4 to 1 an increase in crystallinity is found. The boundary between decreasing and increasing crystallinity at $x=0.3-0.4$ lies at the same position as the transition from tetragonal to cubic phase.

The surface morphologies of the different perovskite samples on mesoporous (ms) $\mathrm{TiO}_{2}$ were investigated using scanning electron microscopy (SEM), see Fig. 3. In all samples part of the underlying $\mathrm{ms}^{-\mathrm{TiO}_{2}}$ is visible; there is thus no complete over-standing layer of perovskite. The coverage was best ( $c a .80 \%$ ) for samples with $x=0.3$ to 0.7 . Clear differences in the perovskite morphology are observed depending on its composition. In $\mathrm{MAPbI}_{3}(\mathrm{Cl})_{y}$ many morphological defects are found, while in the case of $\mathrm{MAPbI}_{2.7} \mathrm{Br}_{0.3}(\mathrm{Cl})_{y}$ the surface appears to be much denser (Fig. 3(a) and (b)). Jeon et al. reported rather similar observations of morphological differences between $\mathrm{FAPbI}_{3}$ and $\left(\mathrm{FAPbI}_{3}\right)_{0.85}\left(\mathrm{MAPbBr}_{3}\right)_{0.15}$, namely, that $\mathrm{Br}$ improves the formation of dense, defect free perovskite films. ${ }^{2}$

\section{Optical absorption and emission}

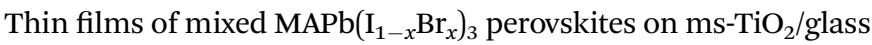
substrates display a gradual change of color when the fraction $\mathrm{Br}$ is increased, from dark brown $(x=0)$ to yellow $(x=1)$, see the pictures in Fig. 4. The corresponding shifts in optical spectra are shown in Fig. 4(a). The absorption onset of $\operatorname{MAPb}\left(\mathrm{I}_{1-x} \mathrm{Br}_{x}\right)_{3}(\mathrm{Cl})_{y}$ changed systematically from $780 \mathrm{~nm}$ to $540 \mathrm{~nm}$ with increasing $\mathrm{Br}$ fraction, consistent with observations in recent studies. ${ }^{\mathbf{4 1 1 , 2 5}}$ Notably, crystalline bulk $\mathrm{MAPbI}_{3}$ is also reported to have a higher absorption onset of about $820 \mathrm{~nm} .^{22}$ The optical band gaps were extracted from a Tauc plots, presented in Fig. S8 in ESI. $\dagger$ Based on this procedure optical bandgaps of $1.60 \mathrm{eV}$ and $2.33 \mathrm{eV}$ in were determined for $\mathrm{MAPbI}_{3}(\mathrm{Cl})_{y}$ and $\mathrm{MAPbBr}_{3}(\mathrm{Cl})_{y}$, respectively, and the bandgaps of the intermediate compositions $\operatorname{MAPb}\left(\mathrm{I}_{1-x} \mathrm{Br}_{x}\right)_{3}(\mathrm{Cl})_{y}$ vary rather linearly between these numbers (see Fig. 4(b)). The values found here are slightly larger than those reported by Noh et al. and Suarez et al. in similar studies. ${ }^{\mathbf{4 , 1 1}}$

An interesting observation is that the gradual increase in absorbance at wavelengths below $650 \mathrm{~nm}$ for $x=0.0$ to 0.2 , a feature which is frequently found in $\mathrm{MAPbI}_{3}$ thin films, is absent for $x=0.3$ to 0.5 . The origin of this absorption is not well understood, but it is possibly due to the presence of amorphous OIHP, left after incomplete reaction. ${ }^{26}$ Absence of this absorbance can then be attributed to formation of more crystalline OIHPs for films with $\mathrm{Br}$ fraction $x=0.3$ to 0.5 (although it is noted that the integrated XRD intensities do not show significant changes in this range (Fig. 2(d))). For $x=0.6$ to 1.0, the onset wavelength of the gradual increase in absorbance changes from 550 to $480 \mathrm{~nm}$.

Photoluminescence (PL) spectra were measured on aged $\operatorname{MAPb}\left(\mathrm{I}_{1-x} \mathrm{Br}_{x}\right)_{3}(\mathrm{Cl})_{y}$ samples at around $30{ }^{\circ} \mathrm{C}$ for 20 days, 

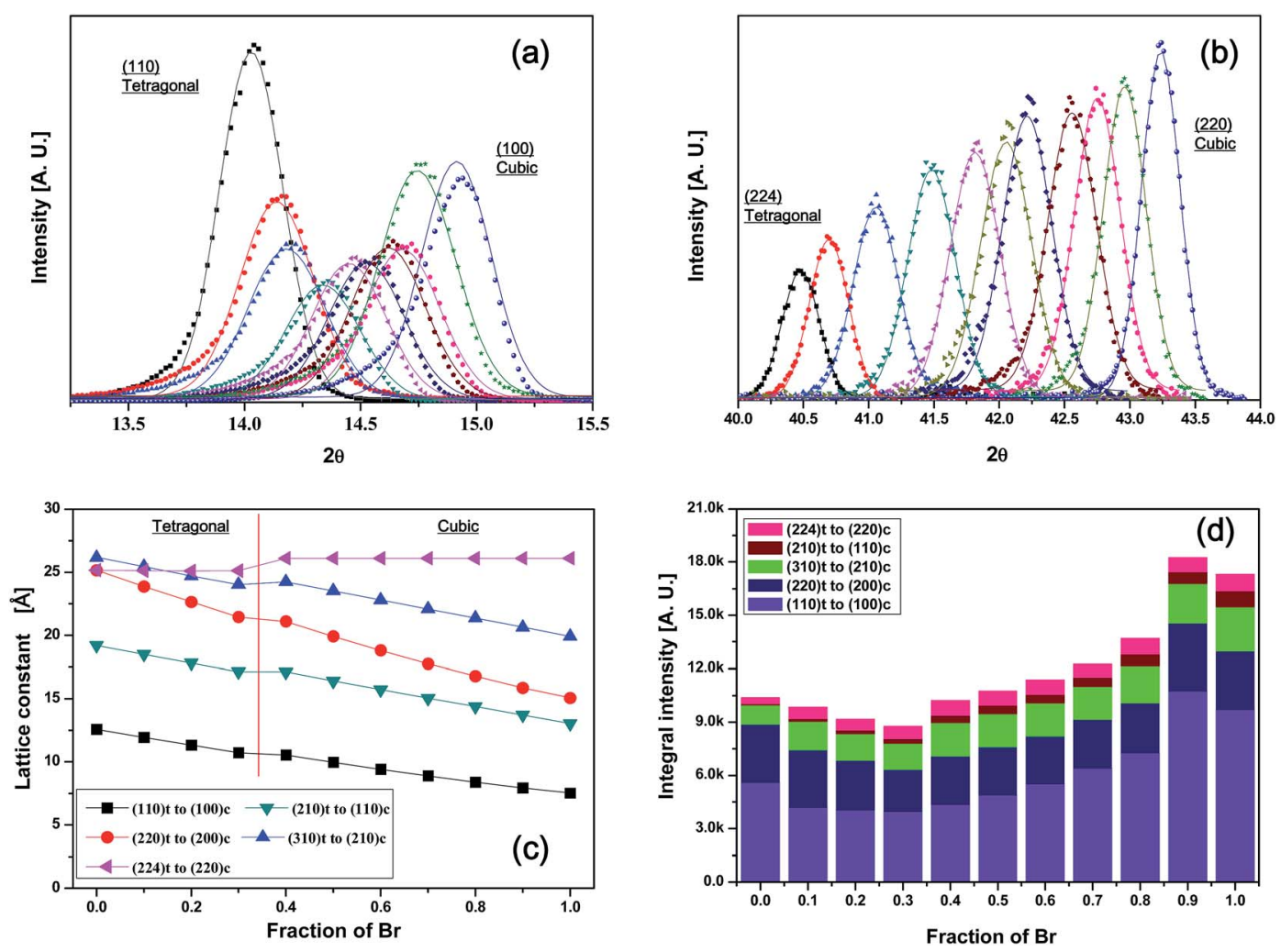

Fig. 2 Transition of the tetragonal to the cubic phase in XRD diffractograms of $\mathrm{MAPb}\left(\mathrm{I}_{1-x} \mathrm{Br}_{x}\right)_{3}(\mathrm{Cl})_{y}$, for $x=0 \% \mathrm{Br}$ to $100 \% \mathrm{Br}$ in $10 \%$ steps (from left to right), shown for (a) the (110)t peak to (100)c peak and (b) (224)t to (220)c. (c) Calculated lattice constants and (d) calculated crystalline population for variable ratio of $\mathrm{Br}$ substitution of OIHPs.

see Fig. 4(c) and S5. $\dagger$ Sadhanala et al. found that fresh $\operatorname{MAPb}\left(\mathrm{I}_{1-x} \mathrm{Br}_{x}\right)_{3}$ films and 21 days aged films have significantly different PL spectra, suggesting stabilization of the structure upon aging. ${ }^{27}$ We find a systematic change of the emission peak with the fraction of $\mathrm{Br}$, as has been demonstrated previously, ${ }^{25,27,28}$ ranging from $535 \mathrm{~nm}$ for $\mathrm{MAPbI}_{3}(\mathrm{Cl})_{y}$ to $775 \mathrm{~nm}$ for $\mathrm{MAPbBr}_{3}(\mathrm{Cl})_{y}$, see Fig. $4(\mathrm{e})$. In the range $x=0.4$ to 0.9 in $\operatorname{MAPb}\left(\mathrm{I}_{1-x} \mathrm{Br}_{x}\right)_{3}(\mathrm{Cl})_{y}$, however, rather different PL spectra are found: these spectra show a weak emission peak in the expected range between 535 and $700 \mathrm{~nm}$, but a much larger peak at lower wavelength, see Fig. 4(d) (PL spectra without normalization are shown in ESI, Fig. S5 $\dagger$ ). We attribute this to energy transfer from the mixed $\operatorname{MAPb}\left(\mathrm{I}_{1-x} \mathrm{Br}_{x}\right)_{3}(\mathrm{Cl})_{y}$ phase to a small fraction of $\mathrm{MAPbI}_{3}$ nanocrystals, which subsequently emits. The emission is blue shifted compared to that found for the $\operatorname{MAPbI}_{3}(\mathrm{Cl})_{y}$ sample, which is due to either a small fraction of $\mathrm{Br}$ in the nanocrystals or the small size of the $\mathrm{MAPbI}_{3}$ nanocrystals, so small that the bandgap is increased due to quantum-size effects (quantum confinement effects). ${ }^{29}$

\section{X-ray photoelectron spectroscopy (XPS) studies}

Valence band (VB) spectra of the series of $\operatorname{MAPb}\left(\mathrm{I}_{1-x} \mathrm{Br}_{x}\right)_{3}(\mathrm{Cl})_{y}$ materials deposited on $\mathrm{ms}^{-\mathrm{TiO}_{2}}$ are presented in Fig. 5(a). A close-up of the upper valence band $(+3.5$ to $-2 \mathrm{eV}$ energy range) is shown in the insert and includes a linear extrapolation and an indication of the experimental spectral edge as described in the
Experimental section. We can observe that the valence band for the present set of samples shift to higher binding energy versus the Fermi level when the amount of bromine increases in the material. In such comparisons, it is important to remember that the observed Fermi level might be sensitive to subtle variations such as bulk doping and surface states. A difference in valence band edge of about $0.5 \mathrm{eV}$ between $\mathrm{MAPbI}_{3}(\mathrm{Cl})_{y}$ and $\operatorname{MAPbBr}_{3}(\mathrm{Cl})_{y}$ is observed.

Using the valence band data from XPS and the bandgap determined from optical absorption, we can construct the energy diagrams presented in Fig. 5(b). Increase of Br content in $\operatorname{MAPb}\left(\mathrm{I}_{1-x} \mathrm{Br}_{x}\right)_{3}(\mathrm{Cl})_{y}$ leads to a decrease in the $\mathrm{VB}$ energy and an increase in the conduction band (CB) level. The procedure used here indicates that the shift in VB is slightly more pronounced than the shift in CB.

\section{Time-correlated single photon counting (TCSPC)}

To gain further insight into the luminescence properties, we measured time-resolved emission of $\operatorname{MAPb}\left(\mathrm{I}_{1-x} \mathrm{Br}_{x}\right)_{3}(\mathrm{Cl})_{y}$ samples. The main results are summarised in Fig. 6. For samples on mesoporous $\mathrm{TiO}_{2}$ with different fractions of $\mathrm{Br}(x=$ $0,0.1,0.4,0.7$ and 1), the decay traces are given in Fig. 6(a). Clearly, the observed decays are not single exponential, but are well-fitted using a bi-exponential function. The obtained lifetimes and amplitudes are shown in Fig. 6(b) and (c), respectively. As a general trend, increasing the $\mathrm{Br}$ fraction leads to 

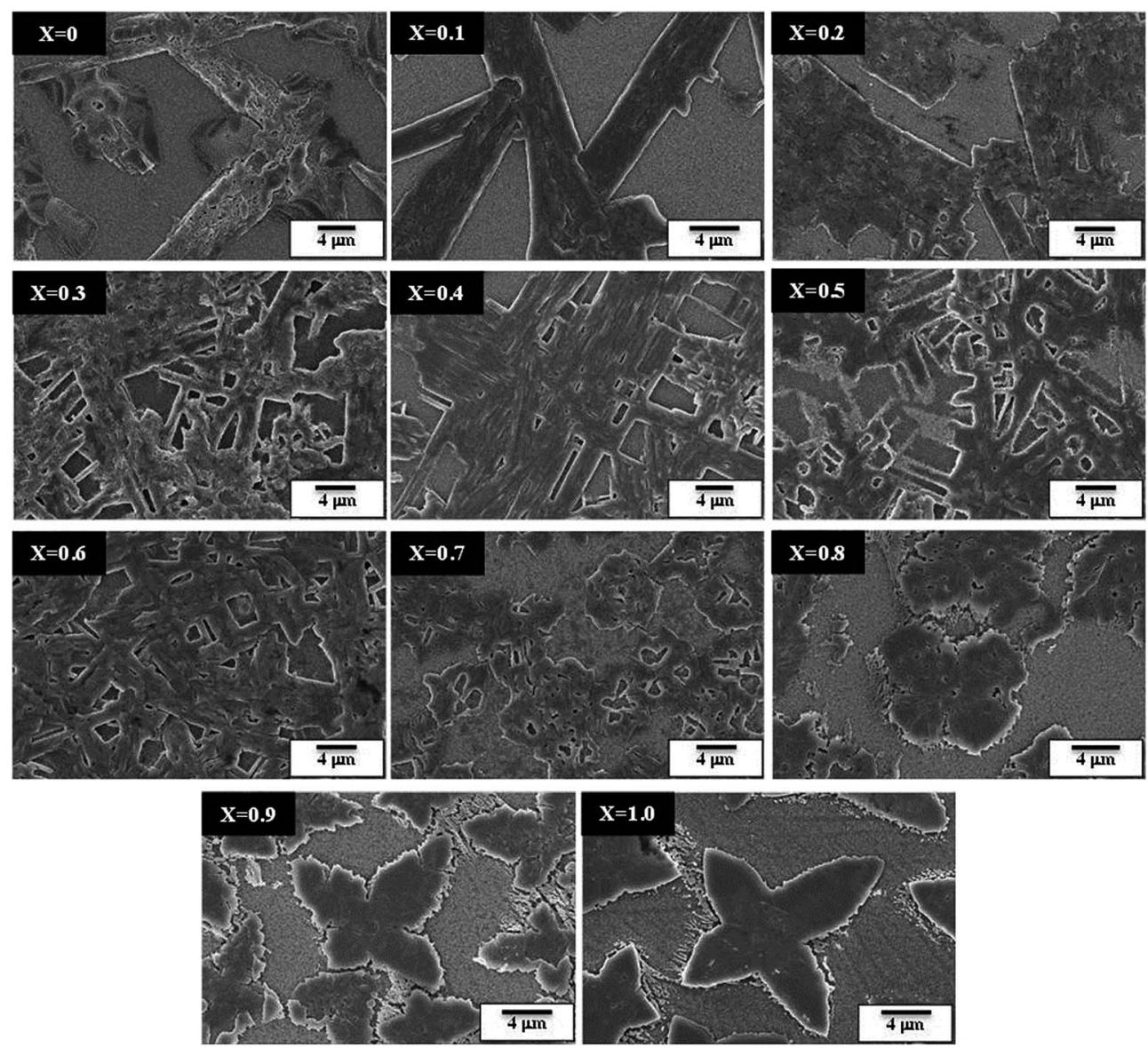

Fig. 3 Top view SEM images ( $4 \mu \mathrm{m}$ scales, horizontal bars) of the different $\mathrm{CH}_{3} \mathrm{NH}_{3} \mathrm{~Pb}\left(\mathrm{I}_{1-x} \mathrm{Br}_{x}\right)_{3}\left(\mathrm{Cl}_{y}\right.$ perovskite deposited on a mesoscopic $\mathrm{TiO}{ }_{2} /$ glass substrate.

significantly faster luminescence decay. A very long-lived component ( $25 \%$ amplitude, $\left.\tau_{2}=3.5 \mu \mathrm{s}\right)$ is found for perovskite with a Br mole fraction of 0.1. The longer of the fitted lifetimes components $\tau_{2}$ changes from 1.0 via $3.5,0.9,0.5$ to $0.1 \mu \mathrm{s}$ when increasing $x$ from 0 to 1 , while the corresponding decreases for the faster component $\tau_{1}$ is from $0.18 \mu$ s to $0.01 \mu \mathrm{s}$. A possible explanation for the bi-exponential decay is that part of the perovskite material is in direct contact with mesoscopic $\mathrm{TiO}_{2}$, and shows a short lifetime due to electron injection, ${ }^{31}$ while the over-standing layer of perovskite is not able to inject directly and gives longer PL lifetimes. ${ }^{32}$ This idea is strengthened by measurements of perovskite films on glass substrates. As can be seen in Fig. 6(g) and (h) for $\mathrm{MAPbI}_{3}(\mathrm{Cl})_{y}$ and $\mathrm{MAPbI}_{2.7} \mathrm{Br}_{0.3}(\mathrm{Cl})_{y}$ respectively, both perovskite samples on glass substrates, show very long lifetimes $\left(\tau_{2}=1.2 \mu \mathrm{s}\right)$, which is indicative of highquality photovoltaic material. ${ }^{33}$ These films are presumably structurally similar to the overstanding layers of perovskite films deposited on mesoscopic scaffold layers. Surprisingly, perovskites on $\mathrm{Al}_{2} \mathrm{O}_{3}$ scaffold layers shows a significant part of rapid luminescence quenching. In this case electron injection cannot take place. Rapid quenching must be induced by the mesoscopic structure, or by interface states at the $\mathrm{Al}_{2} \mathrm{O}_{3}$. Aristidou et al. ${ }^{34}$ found a fast quenching process for $\mathrm{MAPbI}_{3}$ on mesoscopic $\mathrm{Al}_{2} \mathrm{O}_{3}$ that is related to the generation of superoxide
$\left(\mathrm{O}_{2}{ }^{-}\right)$on the perovskite surface formed in a photoinduced reduction process of oxygen. Further detailed studies are, however, needed to resolve the precise origin of rapid emission quenching in our case.

When conducting the TCSPC measurement of mixed $\mathrm{I} / \mathrm{Br}$ perovskites on $\mathrm{TiO}_{2}$, the kinetics was observed to change during the course of the data acquisition. Early, quick measurements showed very long lifetimes, which became faster with increasing measurement times. For samples with $\mathrm{Al}_{2} \mathrm{O}_{3}$ and glass as substrate, however, no such trend was observed. This is illustrated in Fig. 6(d)-(f), where the fitted lifetimes are plotted against the irradiation time during the measurement (given as accumulated counts in the maximum channel). A light-induced modification of mixed-halide perovskites has recently been reported by Hoke et al. ${ }^{35}$ They reported that observed fluorescence changes are accompanied by changes in the XRD pattern and are thus assumed to involve structural modifications and segregation into two crystalline phases, including an iodiderich (I-rich) one acting as quencher for the high-energy states. An important observation in our work is that light-induced changes were only visible on $\mathrm{ms}^{-\mathrm{TiO}_{2}}$ as a substrate, not on

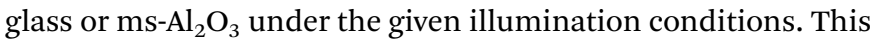
may hint at the role of charges that are required for the formation of I-rich OIHP centers. 

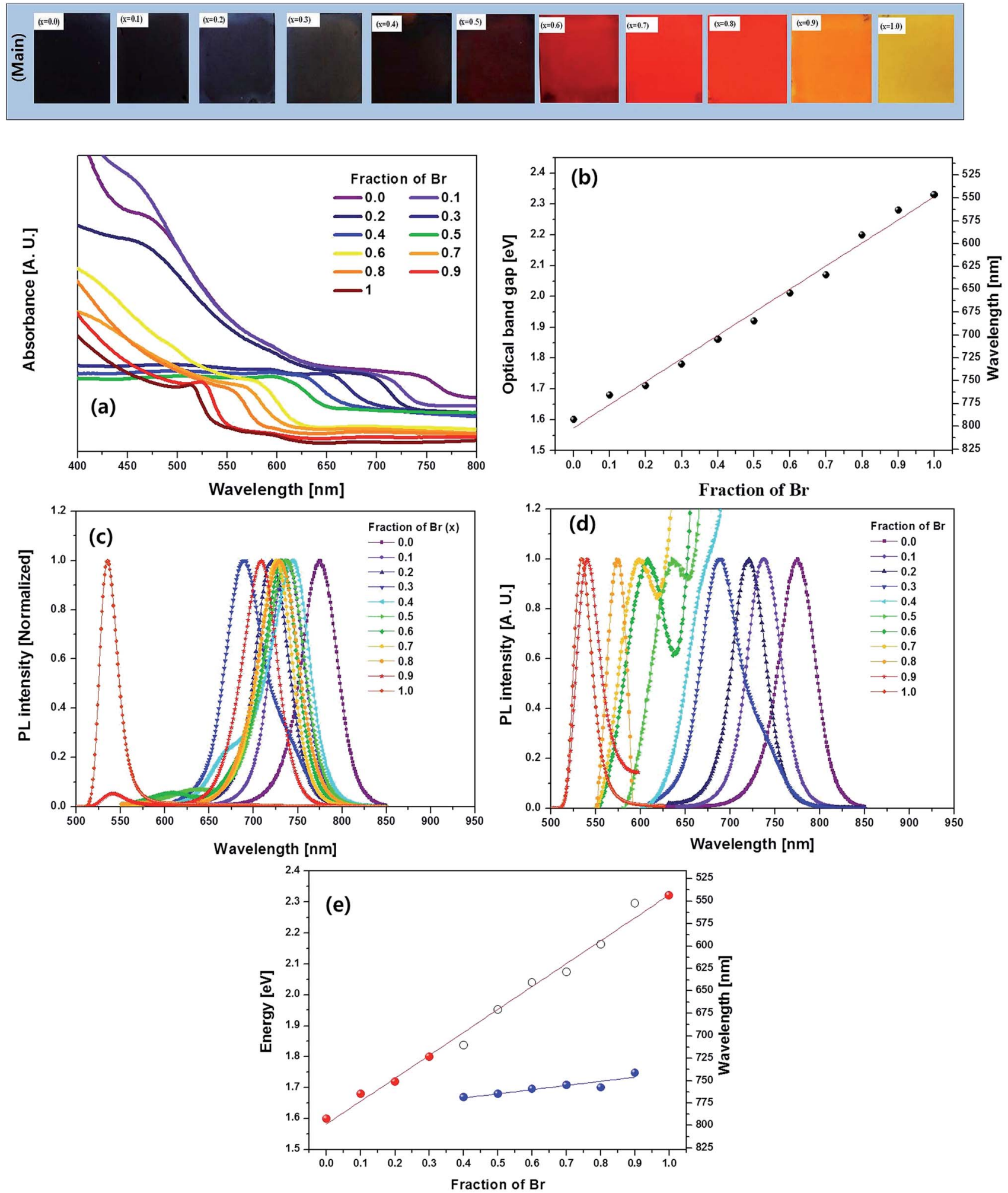

Fig. 4 Top: Optical photographs of $\mathrm{MAPb}\left(\mathrm{l}_{1_{-}} \mathrm{Br}_{x}\right)_{3}(\mathrm{Cl})_{y}$ films. (a) UV-vis absorption spectra of these samples. (b) Optical bandgap as function of $\mathrm{Br}$-fraction in $\mathrm{MAPb}\left(\mathrm{I}_{1-x} \mathrm{Br}_{x}\right)_{3}(\mathrm{Cl})_{y}$. (c) Photoluminescence spectra for the same films (normalized at maximum emission peak). (d) PL spectra of $\mathrm{MAPb}\left(I_{1-x} \mathrm{Br}_{x}\right)_{3}\left(\mathrm{Cl}_{y}\right)$ films scaled for bandgap emission. (e) $\mathrm{PL}$ emission peak energy as function of $\mathrm{Br}$-fraction in $\mathrm{MAPb}\left(\mathrm{I}_{1-x} \mathrm{Br} r_{x}\right)_{3}(\mathrm{Cl})_{y}$.

Toluene addition to OIHP precursor was found to improve crystallinity, coverage area and density of the films for solar cell application. This effect was investigated by UV-vis spectra, XRD,
SEM images and solar cell performances, reported in ESI, Fig. S9 to S11. $\dagger$ Toluene addition in OIHP precursor also gave slightly better $\mathrm{PL}$ lifetimes $\left(\mathrm{MAPbI}_{3}(\mathrm{Cl})_{y} / \mathrm{Al}_{2} \mathrm{O}_{3} /\right.$ glass: around 1.4 

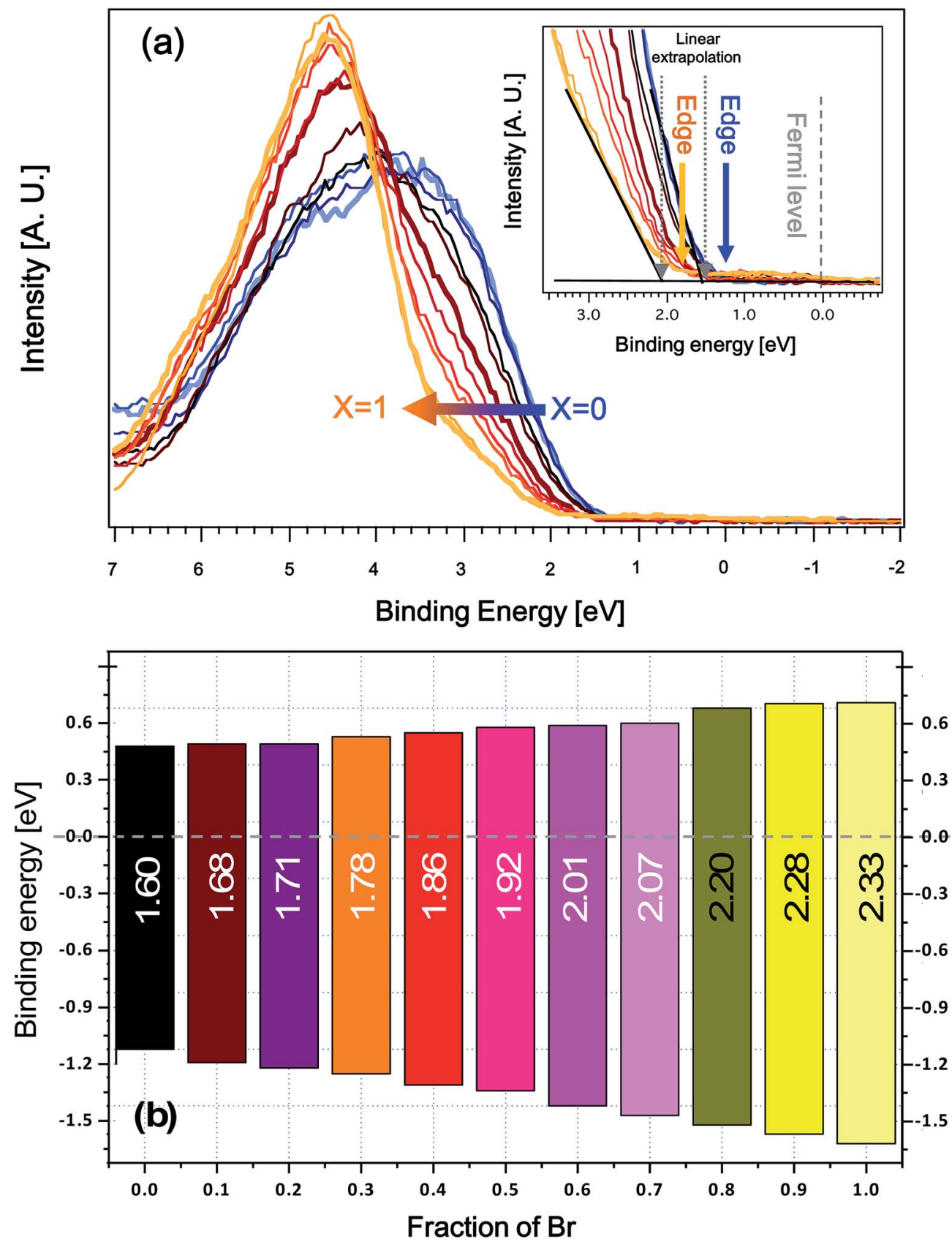

Fig. 5 (a) Valence levels spectra of the $\mathrm{MAPb}\left(\mathrm{I}_{1-x} \mathrm{Br}_{x}\right)_{3}(\mathrm{Cl})_{y}$ series measured by XPS with a photon energy of $1486.6 \mathrm{eV}$. Inset: zoom of the upper valence band ( +3.5 to $-2 \mathrm{eV}$ energy range) including a linear extrapolation and an indication of the experimental spectral edge for the $\mathrm{MAPb} / 3$ and

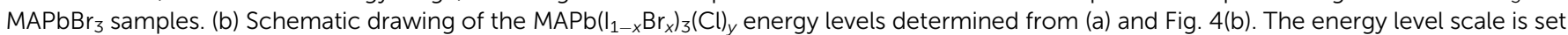
versus the Fermi level using the experimental spectral edge (full arrows), i.e. $0.4 \mathrm{eV}$ were removed from the linear extrapolation energies (dashed arrows).

$\mu \mathrm{s}\left(\tau_{2}\right)$ and $\mathrm{MAPbI}_{2.7} \mathrm{Br}_{0.3}(\mathrm{Cl})_{y} / \mathrm{Al}_{2} \mathrm{O}_{3}$ /glass: around $\left.0.8 \mu \mathrm{s}\left(\tau_{2}\right)\right)$. The fitting values are shown in Fig. S7(c) and (d). $\dagger$

\section{Solar cell performance}

The solar cell performance of $\operatorname{MAPb}\left(\mathrm{I}_{1-x} \mathrm{Br}_{x}\right)_{3}(\mathrm{Cl})_{y}$ with a low fraction of $\mathrm{Br}(0$ to $10 \%)$ was tested. In this regime, the differences in light harvesting efficiency due to the change in bandgap were not significant. In Fig. 7, $J-V$ and IPCE curves of solar cells using $\mathrm{ms}^{-\mathrm{TiO}_{2}}$ scaffold layer are summarized. Short-circuit current densities calculated by integration of IPCE results are in good accordance with experimental $J_{\mathrm{sc}}$ data under simulated sunlight. The open-circuit potential $\left(V_{\mathrm{oc}}\right)$ and the short-circuit photocurrent density $\left(J_{\mathrm{sc}}\right)$ increased from 0.68 to $0.82 \mathrm{~V}$ and from 13.7 to $21.6 \mathrm{~mA} \mathrm{~cm}{ }^{-2}$, respectively, with an increase of $\mathrm{Br}$ content from 0 to $10 \%$. The effect of Br content from 0 to $10 \%$ is also clearly seen in IPCE curves in the plateau values that increase, and in the slight blue shift 

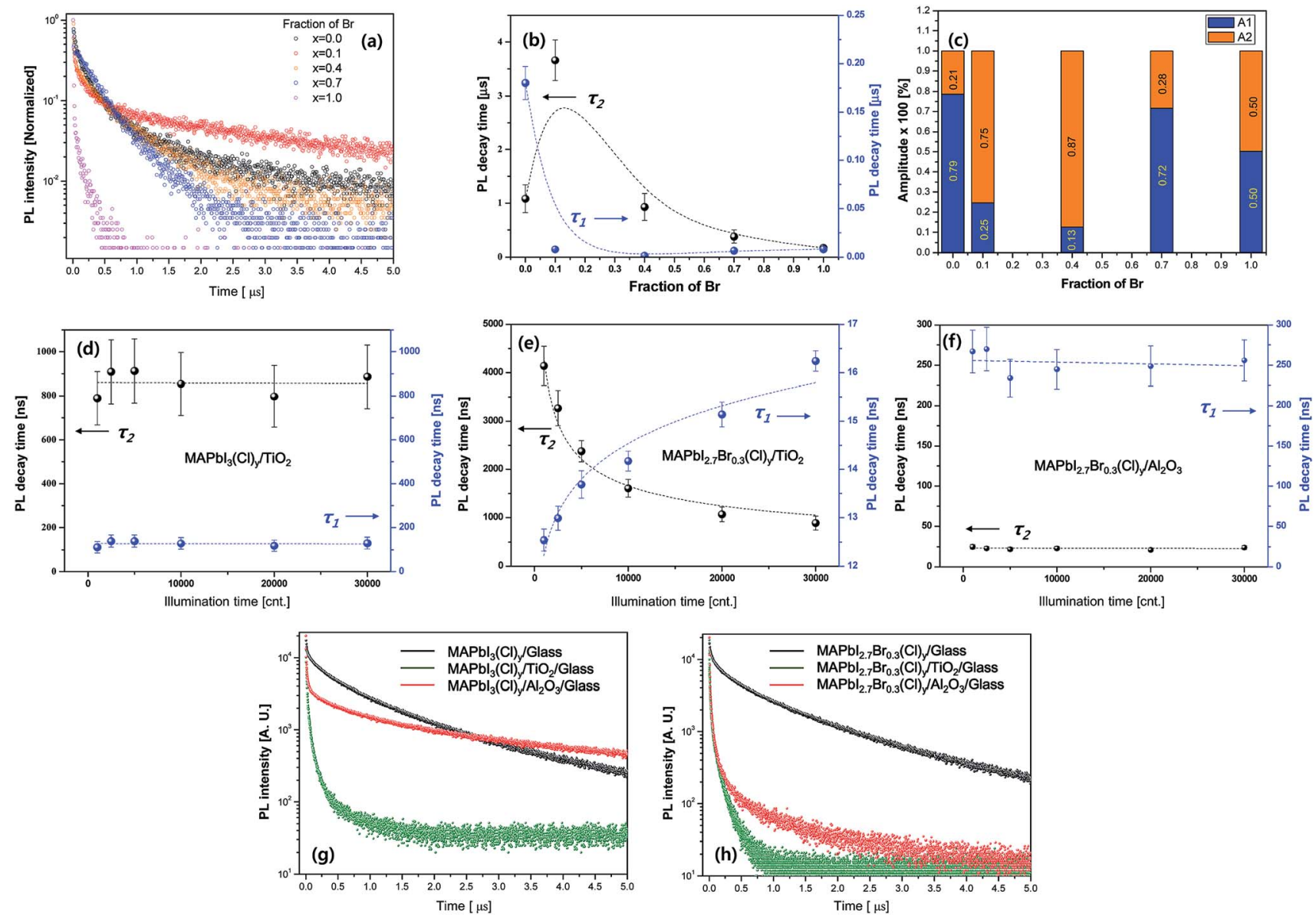

Fig. 6 Time-Correlated Single Photon Counting (TCSPC) results at 2500 counts of $\mathrm{MAPb}\left(\mathrm{l}_{1-x} \mathrm{Br}{ }_{x}\right)_{3}(\mathrm{Cl})_{y}$ films. (a) TCSPC results for variation of fraction of $\mathrm{Br}$ on OlHPs $/ \mathrm{TiO}_{2}\left(x=0.0,0.1,0.4,0.7\right.$ and 1.0) (b) PL decay time constants $\tau_{1}$ and $\tau_{2}$ obtained from biexponential fits of data shown in (a). (c) Fitted amplitudes $\mathrm{A} 1$ and $\mathrm{A} 2$ from the same, (d) effect of illumination time on $\mathrm{PL}$ decay time constants for $\mathrm{MAPbl}_{3}(\mathrm{Cl})_{y} / \mathrm{TiO}{ }_{2}($ the amplitudes are constant at $\mathrm{A} 179 \%$ and $\mathrm{A} 2 \mathrm{21 \%}$ ), (e) effect of illumination time on PL decay time constants for $\mathrm{MAPbl}_{2.7} \mathrm{Br}_{0.3}\left(\mathrm{Cl}_{\mathrm{y}}\right) / \mathrm{TiO} \mathrm{O}_{2}$ (the amplitudes are constant at $\mathrm{A} 125 \%$ and $\mathrm{A} 2 \mathrm{75 \%}$ ). (f) Effect of illumination time on PL decay time constants for $\mathrm{MAPb} \mathrm{I}_{2.7} \mathrm{Br}_{0.3}\left(\mathrm{Cl}_{\mathrm{y}}\right) / \mathrm{Al}_{2} \mathrm{O}_{3}$ (the amplitudes are constant at $\mathrm{A} 150 \%$ and $\mathrm{A} 250 \%$ ). TCSPC results at 20000 counts on (g) $\mathrm{MAPbl}_{3}(\mathrm{Cl})_{y}$ and (h) $\mathrm{MAPbl}_{2.7} \mathrm{Br}_{0.3}\left(\mathrm{Cl}_{y}\right)$ with different substrates as indicated.

of the photocurrent onset edges from $800 \mathrm{~nm}$ to $778 \mathrm{~nm}$ in Fig. 7(b). We believe that these enhancements are related to the denser perovskite structure with lower amount of defects found for the $10 \% \mathrm{Br}$ substituted OIHP. These results may also be correlated with TCSPC experiments that show faster initial decay for the $10 \% \mathrm{Br}$ perovskite, which may be indicative of more efficient electron injection in the mesoporous $\mathrm{TiO}_{2}$, as well as a longer lived photoluminescence tail, which may indicate better perovskite quality in the overstanding layer. $^{32}$

The fill factors (FF) of the perovskite solar cells using ms$\mathrm{TiO}_{2}$ scaffold layer are poor, ranging from 0.35 for $\mathrm{MAPbI}_{3}(\mathrm{Cl})_{y}$ to 0.48 ( $5 \% \mathrm{Br}$ sample). We attribute the low $\mathrm{FF}$ to the poor overstanding OIHP layer that covers only part of the $\mathrm{ms}^{-\mathrm{TiO}_{2}}$ scaffold (see Fig. 3 and S10(a,b,e and f) $\dagger$ ). This implies that there is much contact between the spiro-OMeTAD hole conducting material (HTM) and the $\mathrm{ms}^{-\mathrm{TiO}_{2}}$, giving rise to significant electron/hole recombination.
The use of an ms- $\mathrm{Al}_{2} \mathrm{O}_{3}$ scaffold layer has been reported to enhance $V_{\text {oc }}$ and PCE of hybrid perovskite solar cells. ${ }^{\mathbf{1 0}}$ Recombination between $\mathrm{ms}^{-\mathrm{TiO}_{2}}$ to HTM is prevented in this device structure. Using $\mathrm{Al}_{2} \mathrm{O}_{3}$ scaffold layer in combination with $\mathrm{MAPbI}_{3}(\mathrm{Cl})_{y}$ and $\mathrm{MAPbI}_{2.7} \mathrm{Br}_{0.3}(\mathrm{Cl})_{y}$, we obtained much improved PCE values of $8.0 \%$ and $14.2 \%$, respectively. A possible explanation is that rapid trapping of one charge carrier occurs in case of the presence of an $\mathrm{Al}_{2} \mathrm{O}_{3}$ scaffold layer, as may be deducted from TCSPC results. This can be beneficial charge separation. ${ }^{34}$ There is a significant hysteresis in the $J-V$ curves for forward and reverse scan these devices. Interestingly, the composition of the perovskite had a large effect on the degree of hysteresis. For $\mathrm{MAPbI}_{3}(\mathrm{Cl})_{y} 30 \%$ difference in the calculated PCE value was found (forward (short circuit current to open circuit voltage): $5.6 \%$ and backward (open circuit voltage to short circuit current): $8.0 \%$ ), while for $\mathrm{MAPbI}_{2.7} \mathrm{Br}_{0.3}(\mathrm{Cl})_{y}$ it was less than $10 \%$ (PCE forward: $14.2 \%$ and backward: $12.8 \%$ ). This different $J-V$ 

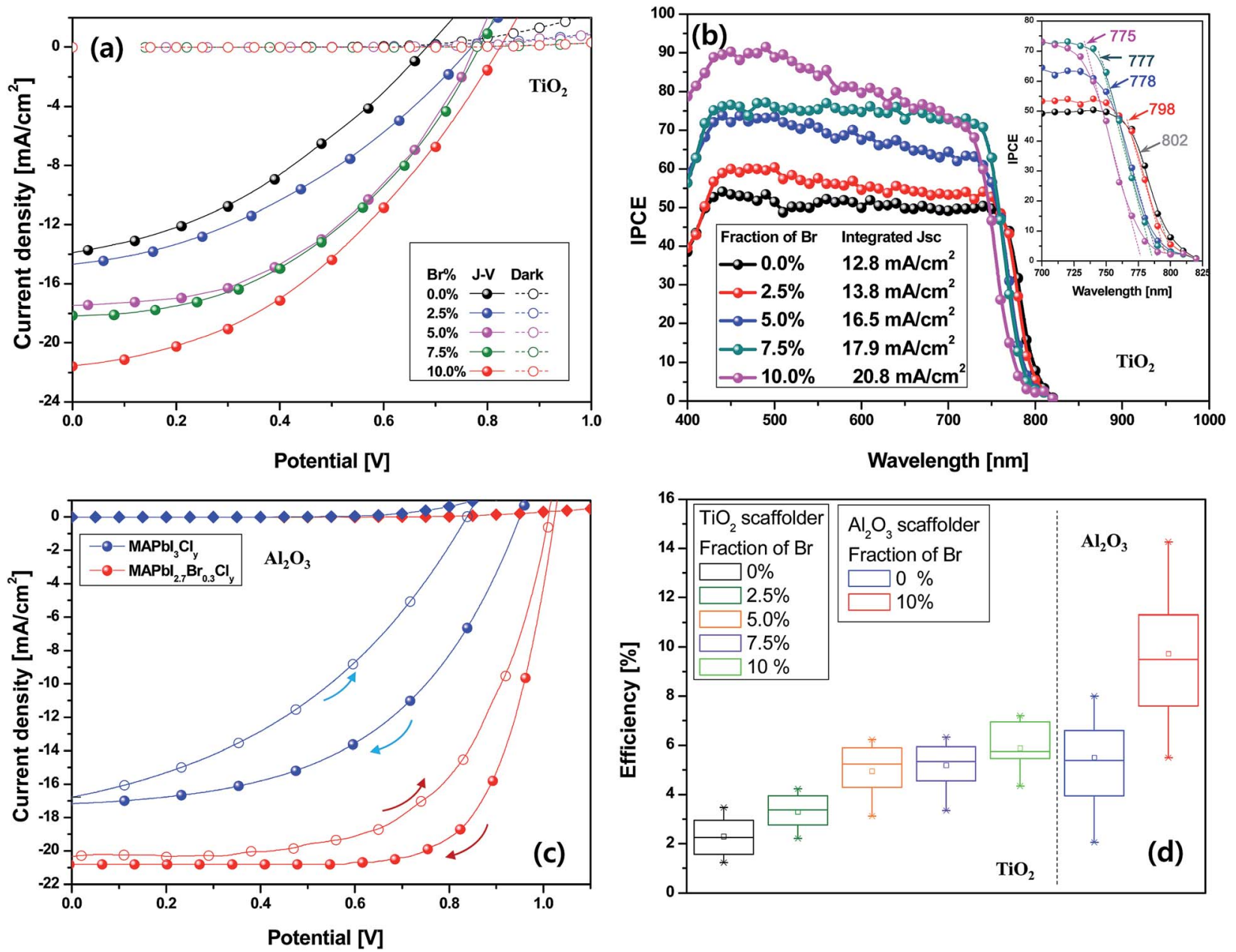

Fig. 7 Solar cell performances for different ratio of $\mathrm{Br}$ substituted OIHPs; (a) J-V curve $\left(\mathrm{TiO}_{2} \mathrm{scaffold}\right.$ layer), (b) IPCE curves (TiO 2 scaffold layer), (c) J-V curves of $\mathrm{MAPbl}_{3}\left(\mathrm{Cl}_{y}\right)$ and $\mathrm{MAPbl}_{2.7} \mathrm{Br}_{0.3}\left(\mathrm{Cl}_{y}\right)\left(\mathrm{Al}_{2} \mathrm{O}_{3}\right.$ scaffold layer), (d) summary of $\mathrm{PCE}$ values obtained for perovskite solar cells with $\mathrm{TiO}{ }_{2}$ or $\mathrm{Al}_{2} \mathrm{O}_{3}$ scaffold layer with different fractions of $\mathrm{Br}$.

hysteresis can be attributed to the improved quality of OIHP film that contains a fraction of $\mathrm{Br}$.

\section{Conclusion}

A convenient 1-step synthesis method for the mixed hybrid perovskite $\mathrm{MAPb}\left(\mathrm{I}_{1-x} \mathrm{Br}_{x}\right)_{3}(\mathrm{Cl})_{y}$, using $\mathrm{PbCl}_{2}$ as lead source, was investigated. The boundary between tetragonal and cubic crystalline phase was found to occur between $x=0.3$ and 0.4 . The optical bandgap varied linearly with the bromide fraction $x$ from 1.60 to $2.33 \mathrm{eV}$. PL spectra showed the same gradual change, however, at intermediate $x$-values additional and stronger emission was found at lower energy, attributed to energy transfer of a small fraction of I-rich OIHP quantum dots.

Time-resolved single-photon counting investigations suggest that inclusion of bromide leads to improved electron injection from hybrid perovskite into mesoporous $\mathrm{TiO}_{2}$. Prolonged excitation during this measurement led to faster decay kinetics of bromide containing perovskites on $\mathrm{TiO}_{2}$ scaffold, while they were unchanged on mesoscopic $\mathrm{Al}_{2} \mathrm{O}_{3}$. Best solar cell results were obtained for $\operatorname{MAPb}\left(\mathrm{I}_{1-x} \mathrm{Br}_{x}\right)_{3}(\mathrm{Cl})_{y}$ with $x=0.1$ on mesoscopic $\mathrm{Al}_{2} \mathrm{O}_{3}$ scaffold layers, yielding $14 \%$ efficiency.

\section{Methods}

\section{Materials and sample fabrication for characterization}

MAI was synthesized by reacting $360 \mathrm{~mL}$ methylamine $(40 \%$ in water, Sigma Aldrich), $280 \mathrm{~mL}$ methylamine (40\% in methanol, TCI) and $40 \mathrm{~mL}$ of hydroiodic acid (without stabilizer, distilled $57 \mathrm{wt} \%$ in water, Aldrich) in a $1000 \mathrm{~mL}$ round bottom flask at around $0{ }^{\circ} \mathrm{C}$ for $5-7 \mathrm{~h}$ with stirring. The precipitate was recovered by evaporation at $70{ }^{\circ} \mathrm{C}$ for $3 \mathrm{~h}$. The MAI was washed with diethyl ether by stirring the solution for $30 \mathrm{~min}$, which was repeated three times then finally dried at $70{ }^{\circ} \mathrm{C}$ in a vacuum oven for $24 \mathrm{~h}$. The yellowish colored MAI (MW 158.96) product was obtained. MABr (MW 111.97) was synthesized as described elsewhere. ${ }^{11}$ Precursor solutions $\operatorname{MAPbI}_{3}(\mathrm{Cl})_{y}, \quad \operatorname{MAPb}\left(\mathrm{I}_{1-x} \mathrm{Br}_{x}\right)_{3}(\mathrm{Cl})_{y}$ and $\mathrm{MAPbBr}_{3}(\mathrm{Cl})_{y}$ were formed by mixing a ratio of three to one of MAI (0.9 to $0.0 \mathrm{M})$ and $\mathrm{MABr}(0.0$ to $0.9 \mathrm{M})$ with $\mathrm{PbCl}_{2}(0.3 \mathrm{M})$ in dimethylformamide (DMF)/dimethyl sulfoxide (DMSO) $(7 / 3=$ $\mathrm{v} / \mathrm{v}$ ). $\mathrm{PbCl}_{2}$ was first completely dissolved by stirring on a hot-plate 
set at $70-80{ }^{\circ} \mathrm{C}$ for few hours, after then they reacted with MAI or MABr (mixed MAX: $\mathrm{X}=\mathrm{Br}$ and I) for 2 hours. Finally, tetrahydrofuran (THF, $10 \mathrm{vol} \%$ ) was added. $\mathrm{TiO}_{2}$ nanoparticles were deposited on microscope glass by spin coating method at 3000 rpm for $30 \mathrm{~s}$. The $\mathrm{TiO}_{2}$ suspension was Dyesol paste (DSL $30 \mathrm{NR}$ D) diluted with terpinol $25 \mathrm{wt} \%$ in ethanol $(1: 4=\mathrm{g} / \mathrm{g})$. The $\mathrm{TiO}_{2}$ nanoparticle coated microscope glass was annealed onto hot plate at $550{ }^{\circ} \mathrm{C}$ for $30 \mathrm{~min}$. The film thickness was approximately $300 \mathrm{~nm}( \pm 50 \mathrm{~nm})$ as determined by a Dektak3 profiler. Unless stated otherwise, OIHP precursors are coated onto $\mathrm{TiO}_{2} /$ glass substrate by spin-coating method at $1500 \mathrm{rpm}$ for $30 \mathrm{~s}$. These are annealed onto hot plate at $145{ }^{\circ} \mathrm{C}$ for $30-45 \mathrm{~min}$ in a dry box (humidity $\leqq 20 \%$ ), see Fig. S16. $\dagger$

\section{ATR FT-IR spectra}

ATR FT-IR spectra were obtained from the powders of $\mathrm{MACl}$, MABr, MAI, dried $\mathrm{MAPbBr}_{3}(\mathrm{Cl})_{y}$ and $\mathrm{MAPbI}_{3}(\mathrm{Cl})_{y}$ which were carried on a Nicolet Avatar 370 DTGS spectrophotometer (Thermo Co. LTD., resolution is $0.964 \mathrm{~cm}^{-1}$, scan counting has 300 times per a sample). Background signal was subtracted.

\section{UV-vis-NIR spectra}

To measure UV-visible-NIR absorption spectra, organic-inorganic perovskite coated $\mathrm{TiO}_{2}$ electrodes deposited on working electrode were prepared according to the mention above and the measurements were carried on a Varian Cary 5000 UV-visNIR spectrophotometer. The FTO glass substrate signal was used as calibration background.

\section{Steady-state emission measurements}

Standard steady-state emission spectra were obtained on a Fluorolog-3 instrument (Horiba Jobin Yvon) equipped with double-grating excitation and emission monochromators and a $450 \mathrm{~W}$ Xe lamp as a light source. The emission spectra were corrected for the spectral sensitivity of the detection system by using a calibration file of the detector response. Front-face illumination $\left(30^{\circ}\right.$ with respect to the incident beam) was used to minimize inner-filter effects. The pump laser had setup at relevant wavelength to the valence band of OIHPs. The filters has been setup front of detectors.

\section{Time-correlated single photon counting (TCSPC)}

A detailed description of the experimental setup has been given recently. ${ }^{36}$ Briefly, the sample was excited on the perovskite side with 77.1 ps pulses of $404.6 \mathrm{~nm}$ from a picosecond diode laser (Edinburgh Instruments, EPL-405). Certain measurements were done with $470 \mathrm{~nm}$ excitation (EPL-470). As practically the same results were obtained, we used $404.6 \mathrm{~nm}$ excitation because of the shorter instrument response function due to shorter excitation pulses. The laser pulse energy was very low, $c a .15 \mathrm{pJ}$ and was attenuated even further to reach the desired count rate of ca. 1\%. This ensures low enough excitation to avoid Auger recombination $^{37}$ in OIHPs and that the results are free from pulse pile-up. ${ }^{38,39}$ Measurements where done in reverse mode at 5-10 $\mathrm{MHz}$ and under magic angle polarization. A cutoff filter
(OG590) was used to block stray excitation light. A dilute solution of Ludox was used to record the instrument response function without any filter. No monochromator was used, i.e. all wavelengths transmitted by the cutoff filter were collected, increasing the instrumental sensitivity.

\section{Crystallographic properties}

The OIHP deposited on $\mathrm{TiO}_{2} /$ glass substrate were investigated for crystallographic properties using X-ray diffraction (XRD) with a Siemens diffraktometer D5000 apparatus at room temperature using $\mathrm{CuK} \alpha$ radiation in time period. Diffrac plus $\mathrm{XRD}$ commander program was used to control the instrument. The instrument was set in "detector scan" mode, and the acquisition was done in $\theta-2 \theta$ mode for every $0.02^{\circ}$ increment over the Bragg angle range of $10-60^{\circ}$.

\section{Scanning electron microscopy (SEM)}

Scanning Electron Microscopy (SEM) was performed on a Zeiss (Gemini 1550) microscope having a field emission (FE) electron source and an in-lens detector for secondary electrons. Top view images were recorded using a high tension of $10 \mathrm{kV}$.

\section{X-ray photoelectron spectroscopy (XPS)}

XPS measurements were performed with a Scienta ESCA 300 instrument, using monochromatized AlK $\alpha$ radiation $h \nu=$ $1486.7 \mathrm{eV}$ with an overall instrumental resolution of $0.6 \mathrm{eV}$. The pressure in the analysis chamber was around $1 \times 10^{-8} \mathrm{mbar}$ and the electron take off angle was $90^{\circ}$. The valence spectra presented were binding energy calibrated using the Ti 2 p core level signal from the $\mathrm{TiO}_{2}$ substrate which in this study was set to $459.45 \mathrm{eV}$. This value was obtained by measuring the energy difference between the $\mathrm{Ti} 2 \mathrm{p}$ core level of pure $\mathrm{TiO}_{2}$ and the Fermi level on an Au sample with the same instrument. This calibration was crosschecked with the position of the metallic lead sometimes observed and found at $137.0 \mathrm{eV}$ versus the Fermi level of the $\mathrm{Au}$ sample. Charging and radiation effects were checked for by measuring the specific core level repetitively and was found negligible for all spectra reported in the present investigation. The shape of the VB will depend on the photon energy used. ${ }^{40}$ To evaluate the relative changes in the upper energies of the valence band, we used a linear extrapolation. The linear extrapolation energy is defined as the intersection of a linear extrapolation of outermost experimental valence levels with the baseline. Moreover, in the spectra of $\mathrm{MAPbI}_{3}$ and $\mathrm{MAPbBr}_{3}$ we indicate an experimental spectral edge were the amount of counts above the baseline is less than about one percent of the maximum value at about $4.0 \mathrm{eV}$. For both $\mathrm{MAPbI}_{3}$ and $\mathrm{MAPbBr}_{3}$ we note that the difference between the experimental spectral edge and linear extrapolation energy is close to 0.4 $\mathrm{eV}$. In the present paper, we therefore remove $0.4 \mathrm{eV}$ to the linear extrapolation energy as an estimation of the valence band edge when compared to the Fermi level. ${ }^{30}$ This procedure gives values that relate to literature values of the difference between a Fermi level of $\mathrm{TiO}_{2}$ pinned to the conduction band edge and an anatase bandgap of $3.2 \mathrm{eV}$. 


\section{Fabrication and measurement of solar cell devices}

Fabrication of solar cell device. All experiments are carried out in 30\%-45\% humidity. The OIHP precursors were prepared as follow as in the section of material and sample fabrication for characterization. $\mathrm{MAPbI}_{3} \mathrm{Cl}_{y}, \mathrm{MAPbI}_{3-x} \mathrm{Br}_{x} \mathrm{Cl}_{y}$ and $\mathrm{MAPbBr}_{3} \mathrm{Cl}_{y}$ were formed by mixing a ratio of three to one of MAI $(3.60 \mathrm{M}$ (100\%)-3.24 M (90\%)) and $\operatorname{MABr}(0.00 \mathrm{M}(0 \%)-0.36 \mathrm{M}(10 \%))$ with $\mathrm{PbCl}_{2}(1.2 \mathrm{M})$ in DMF/DMSO $(7 / 3=\mathrm{v} / \mathrm{v})$ on a hot plate of $70-80{ }^{\circ} \mathrm{C}$ for $90 \mathrm{~min}$. For the solar cell devices, tetrahydrofuran (THF)/toluene $(1 / 2=\mathrm{v} / \mathrm{v})$ mixed solvent was added to the OIHP precursor and it is consisted of $85 \%$ precursor and $15 \% \mathrm{THF} /$ toluene solvent $(\mathrm{v} / \mathrm{v})$. The effect of toluene on morphology of OIHP has well been investigated in previous report. ${ }^{12}$ All OIHP precursors are kept on $70{ }^{\circ} \mathrm{C}$ on a hot plate during fabrication processes. $\mathrm{TiO}_{2}$ precursor was prepared as follow as in the section of Materials and sample fabrication for characterization. $\mathrm{Al}_{2} \mathrm{O}_{3}$ precursor purchased from Sigma Aldrich which is size of $\sim 50 \mathrm{~nm}$ in isopropanol and diluted with isopropanol as $1: 2$ (v/v). Fluorine-doped tin oxide (FTO) coated glass (Pilkington TEC 15) $15 \Omega \square^{-1}$ was patterned according to etching processes with $\mathrm{Zn}$ powder and $2 \mathrm{M} \mathrm{HCl}$ diluted in water. $\mathrm{TiO}_{2}$ compact layer as electron extracting layer was deposited the film thickness of 40-70 nm onto the eached FTO substrate and temperature of hot plate was kepted at $400-450{ }^{\circ} \mathrm{C}$ during spray pyrolysis deposition process. The prepared $\mathrm{TiO}_{2}$ and $\mathrm{Al}_{2} \mathrm{O}_{3}$ precursors were spincoated for $20 \mathrm{~s}$ at 4000 and $2750 \mathrm{rpm}$, respectively, and dried on a hot plate at $450{ }^{\circ} \mathrm{C}\left(\mathrm{TiO}_{2}\right)$ or $150{ }^{\circ} \mathrm{C}$ $\left(\mathrm{Al}_{2} \mathrm{O}_{3}\right)$ for $30 \mathrm{~min}$. The prepared OIHP precursor was spin coated at $1250 \mathrm{rpm}$ for $20 \mathrm{~s}$ and annealed at $145{ }^{\circ} \mathrm{C}$ for $30-45$ $\mathrm{min}$. The hole transporter was deposited by spin-coating at 1250 rpm for $20 \mathrm{~s}$ using an 8 wt $\%$ 2,20,7,70-tetrakis-( $N, N$-di- $p$ methoxyphenyl-amine)9,9-spirobifluorene (spiro-OMeTAD) in chlorobenzene with added tert-butylpyridine (TBP) and lithium bis(tri-fluoromethanesulfonyl)imide (Li-TFSI) of 80 and 30 mol\%, with respect to spiro-OMeTAD. The final producing spiro-OMeTAD was oxygen doped. ${ }^{41}$ Finally, $150 \mathrm{~nm}$ thick silver electrodes were deposited on top of devices by thermal evaporation at $\sim 10^{-6}$ bar, through a shadow mask.

Power conversion efficiency (PCE). The light source of a solar simulator for measuring the current-voltage $(J-V)$ characteristics was a $300 \mathrm{~W}$ solar simulator (Newport) calibrated to a 1000 $\mathrm{W} \mathrm{m}^{-2}$ light intensity at the $1.5 \mathrm{AM}$ Global condition (1 sun AM $1.5 \mathrm{G}$ illumination) by a certified silicon solar cell (Fraunhofer ISE). The electrical data were recorded with a computer controlled digital source-meter (Keithley Model 2401) with the scan direction from the open-circuit to the short-circuit at a scan rate of $800-1250 \mathrm{mV} \mathrm{s}^{-1} \cdot{ }^{42,43} \mathrm{TiO}_{2}$ scaffold based solar cells were masked during the measurement with an metal mask with a square aperture of $0.2 \mathrm{~cm}^{2}\left(0.10 \mathrm{~cm}^{2}\right.$ for $\mathrm{Al}_{2} \mathrm{O}_{3}$ scaffold based solar cells).

Incident photon to current conversion efficiency (IPCE). The IPCE spectra were recorded with a computer-controlled setup comprised of a xenon lamp (Spectral Products, ASB-XE-175), a monochromator (Spectral Products, CM110), chopped at $30 \mathrm{~Hz}$, a potentiostat (PINE instrument Company, Model AFRDE5) and a lock-in amplifier (SRS830), using white LED bias light. The setup was calibrated with a certified silicon solar cell (Fraunhofer ISE) prior to the measurements. $\mathrm{TiO}_{2}$ scaffold based solar cells were illuminated from the WE side using a black mask with an rectangular aperture of $0.20 \mathrm{~cm}^{2}\left(0.10 \mathrm{~cm}^{2}\right.$ for $\mathrm{Al}_{2} \mathrm{O}_{3}$ scaffold based solar cells). The white LED bias light was approx. 0.08 sun in intensity.

\section{Acknowledgements}

We thank the Swedish Energy Agency, the STandUP for Energy program, the Swedish Research Council (VR), the Göran Gustafsson Foundation, and the Knut and Alice Wallenberg Foundation for financial support. B-w. P. thanks the members of the Korean Scandinavian Scientist Engineers Association (KSSEA) and chairman Dr Keunjae Kim for support and regards, in particular Taeja Kim-Björklund, former chairman in KSSEA of Sweden. Further thanks to Mr Seockjeong Eom, Ambassador in Embassy of Republic of Korea in Sweden.

\section{References}

1 M. A. Green, A. Ho-Baillie and H. J. Snaith, Nat. Photonics, 2014, 8, 506-514.

2 N. J. Jeon, J. H. Noh, W. S. Yang, Y. C. Kim, S. Ryu, J. Seo and S. I. Seok, Nature, 2015, 517, 476-480 Efficiency chart of NREL, http:/www.nrel.gov/ncpv/images/efficiency_chart.jpg.

3 D. B. Mitzi, S. Wang, C. A. Feild, C. A. Chess and A. M. Guloy, Science, 1995, 267, 1473-1476.

4 B. Suarez, V. Gonzalez-Pedro, T. S. Ripolles, R. S. Sanchez, L. Otero and I. Mora-Sero, J. Phys. Chem. Lett., 2014, 5(10), 1628.

5 B. Cai, Y. Xing, Z. Yang, W.-H. Zhang and J. Qiu, Energy Environ. Sci., 2013, 6, 1480-1485.

6 J. H. Heo, D. H. Song and S. H. Im, Adv. Mater., 2014, 26, 8179-8183.

7 Y. Zhao and K. Zhu, J. Am. Chem. Soc., 2014, 136(35), 1224112244.

8 A. Kojima, K. Teshima, Y. Shirai and T. Miyasaka, J. Am. Chem. Soc., 2009, 131(17), 6050.

9 J.-H. Im, C.-R. Lee, J.-W. Lee, S.-W. Park and N.-G. Park, Nanoscale, 2011, 3(10), 4088-4093.

10 M. M. Lee, J. Teuscher, T. Miyasaka, T. N. Murakami and H. J. Snaith, Science, 2012, 338(6107), 643-647.

11 J. H. Noh, S. H. Im, J. H. Heo, T. N. Mandal and S. I. Seok, Nano Lett., 2013, 13(4), 1764-1769.

12 N. J. Jeon, J. H. Noh, Y. C. Kim, W. S. Yang, S. Ryu and S. I. Seok, Nat. Mater., 2014, 13, 897-903.

13 A. Kojima, M. Ikegami, K. Teshima and T. Miyasaka, Chem. Lett., 2012, 41, 397-399.

14 J. L. Knutson, J. D. Martin and D. B. Mitzi, Inorg. Chem., 2005, 44, 4699-4705.

15 K. D. Karlin and D. B. Mitzi, in Prog. Inorg. Chem., John Wiley \& Sons, Inc., New York, 2007, pp. 1-121.

16 B. Philippe, B.-W. Park, R. Lindblad, J. Oscarsson, S. Ahmadi, E. M. J. Johansson and H. Rensmo, Chem. Mater., 2015, 27(5), 1720-1731. 
17 B.-w. Park, B. Philippe, T. Gustafsson, K. Sveinbjörnsson, A. Hagfeldt, E. M. J. Johansson and G. Boschloo, Chem. Mater., 2014, 26(15), 4466-4471.

18 B.-w. Park, S. M. Jain, X. Zhang, A. Hagfeldt, G. Boschloo and T. Edvinsson, ACS Nano, 2015, 9(2), 2088-2101.

19 E. L. Unger, A. R. Bowring, C. J. Tassone, V. L. Pool, A. G. Parker, R. Cheacharoen, K. H. Stone, E. T. Hoke, M. F. Toney and M. D. McGehee, Chem. Mater., 2014, 26(24), 7158-7165.

20 J. You, Z. Hong, Y. Yang, Q. Chen, M. Cai, T.-B. Song, C.-C. Chen, S. Lu, Y. Liu, H. Zhou and Y. Yang, ACS Nano, 2014, 8(2), 1674-1680.

21 T. Baikie, Y. Fang, J. M. Kadro, M. Schreyer, F. Wei, S. G. Mhaisalkar, M. Graetzel and T. J. White, J. Mater. Chem. A, 2013, 1, 5628-5641.

22 Y. Zhao and K. Zhu, J. Phys. Chem. C, 2014, 118(18), 94129418.

23 I. P. Swainson, R. P. Hammond, C. Soullière, O. Knop and W. Massa, Solid State Chem., 2003, 176, 97-104.

24 R. D. Waldron, J. Chem. Phys., 1953, 21, 734.

25 G. E. Eperon, S. D. Stranks, C. Menelaou, M. B. Johnston, L. M. Herz and H. J. Snaith, Energy Environ. Sci., 2014, 7, 982-988.

26 J. J. Choi, X. Yang, Z. M. Norman, S. J. L. Billinge and J. S. Owen, Nano Lett., 2014, 14(1), 127-133.

27 A. Sadhanala, F. Deschler, T. H. Thomas, S. E. Dutton, K. C. Goedel, F. C. Hanusch, M. L. Lai, U. Steiner, T. Bein, P. Docampo, D. Cahen and R. H. Friend, J. Phys. Chem. Lett., 2014, 5, 2501-2505.

28 G. Xing, N. Mathews, S. S. Lim, N. Yantara, X. Liu, D. Sabba, M. Grätzel, S. Mhaisalkar and T. C. Sum, Nat. Mater., 2014, 13, 476-480.

29 G. V. Prakash, K. Pradeesh, R. Ratnani, K. Saraswat, M. E. Light and J. J. Baumberg, J. Phys. D: Appl. Phys., 2009, 42, 185405.
30 T. Leijtens, S. D. Stranks, G. E. Eperon, R. Lindblad, E. M. J. Johansson, I. J. McPherson, H. Rensmo, J. M. Ball, M. M. Lee and H. J. Snaith, ACS Nano, 2014, 8(7), 7147-7155.

31 K. G. Stamplecoskie, J. S. Manser and P. V. Kamat, Energy Environ. Sci., 2015, 8, 208-215.

32 M. De Bastiani, V. D'Innocenzo, S. D. Stranks, H. J. Snaith and A. Petrozza, APL Mater., 2014, 2, 081509.

33 S. D. Stranks, G. E. Eperon, G. Grancini, C. Menelaou, M. J. P. Alcocer, T. Leijtens, L. M. Herz, A. Petrozza and H. J. Snaith, Science, 2013, 342, 341.

34 N. Aristidou, I. Sanchez-Molina, T. Chotchuangchutchaval, M. Brown, L. Martinez, T. Rath and S. A. Haque, Angew. Chem., Int. Ed., 2015, 54, 8208-8212.

35 E. T. Hoke, D. J. Slotcavage, E. R. Dohner, A. R. Bowring, H. I. Karunadasa and D. McGehee, Chem. Sci., 2015, 6, 613-617.

36 A. E. -Zohry, A. Orthaber and B. Zietz, J. Phys. Chem. C, 2012, 116, 26144-26153.

37 G. Xing, N. Mathews, S. S. Lim, N. Yantara, X. Liu, D. Sabba, M. Grätzel, S. Mhaisalkar and T. C. Sum, Nat. Mater., 2014, 13, 476-480.

38 D. V. O'Connor and D. Phillips, Time-Correlated Single Photon Counting, Academic Press, London, 1984.

39 J. R. Lakowicz, Principles of Fluorescence Spectroscopy, Springer, Berlin, 3rd edn, 2006.

40 S. J. H., J. Electron Spectrosc. Relat. Phenom., 1976, 8, 129-137.

41 U. B. Cappel, T. Daeneke and U. Bach, Nano Lett., 2012, 12(9), 4925-4931.

42 R. S. Sanchez, V. G. Pedro, J.-W. Lee, N.-G. Park, Y. S. Kang, I. Mora-Sero and J. Bisquert, J. Phys. Chem. Lett., 2014, 5, 2357-2363.

43 E. L. Unger, E. T. Hoke, C. D. Bailie, W. H. Nguyen, A. R. Bowring, T. Heumuller, M. G. Christoforod and M. D. McGehee, Energy Environ. Sci., 2014, 7, 3690-3698. 